\title{
NativoApp: Realidade aumentada aplicada no resgate cultural da Língua Wai-Wai
} NativeApp: Augmented reality applied in Wai-Wai language cultural rescue

Wilder Silva de Farias, BCC/UFOPA, wilder.fabricio@outlook.com Roberto Pereira do Nascimento, IEG/UFOPA, roberto.nascimento@ufopa.edu.br Marcio José Moutinho da Ponte, IEG/UFOPA, marcio.ponte@ufopa.edu.br

Nattan Lobato, BSI/CORI/UFOPA, nattangmr2@gmail.com Josivan Rodrigues Reis, CORI/UFOPA, josivan.reis@ufopa.edu.br

RESUMO: Devido às constantes mudanças socioambientais que ocorrem na região amazônica aliada ao avanço tecnológico, povos indígenas outrora isolados agora convivem com os costumes contemporâneos e lutam para não verem sua cultura desaparecer e evitar que jovens, aldeados ou não, acabem deixando de lado seus costumes e tradições dado o contato com a cultura urbana. Além disso enfrentam diversas dificuldades na transmissão do conhecimento para as novas gerações bem como no processo educacional e nesse contexto, este trabalho busca por meio de um aplicativo de realidade aumentada promover o resgate cultural e a facilitar o processo de ensino e aprendizagem de crianças e jovens indígenas, transmitindo de forma intuitiva os costumes e língua indígena Wai-Wai.

Palavras-chave: Tecnologia educacional; Educação indígena; Resgate cultural.

ABSTRACT: Due to the constant socio-environmental changes that occur in the Amazon region coupled with technological advancement, once isolated indigenous peoples now live with contemporary customs and struggle not to see their culture disappear and prevent young people, whether or not villages, end up leaving aside their customs and traditions. given the contact with urban culture. In addition, they face several difficulties in transmitting knowledge to new generations as well as in the educational process. In this context, this work seeks through an augmented reality application to promote cultural rescue and to facilitate the teaching and learning process of indigenous children and young people, intuitive transmission of Wai-Wai indigenous language and costumes.

Keywords: Educational technology; Indigenous education; Cultural rescue.

\section{INTRODUÇÃO}

O processo educacional sempre foi um desafio para os profissionais da área da educação, principalmente no que diz respeito aos povos indígenas, pois são povos distintos, com peculiaridades que devem ser preservadas e respeitadas, como manda a Constituição da República Federativa do Brasil de 1988 (CRFB/88), no Título VIII, capítulo VIII que trata da questão dos povos indígenas.

A população indígena segundo o censo 2010 do Instituto Brasileiro de Geografia e Estatística (IBGE, 2010) correspondem a 4\% da população brasileira e a taxa de 
analfabetismo entre os indígenas acima de 15 anos, em língua portuguesa e/ou língua materna ultrapassa os 33\%.

Ademais o contato com povos contemporâneos e suas tecnologias como computadores e smartphones é outro fator preocupante pois resulta em um distanciamento dos costumes indígenas por parte dos mais jovens. Muitos acabam imergindo na cultura urbana e passam a adotar outros costumes, deixam de lado as tradições culturais ocasionando entre outros fatores o esquecimento da língua falada.

É diante dessa série de fatores que se encontram os habitantes da aldeia Mapuera, localizados às proximidades da cidade de Oriximiná, região da Calho Norte do Rio Amazonas, especificamente à margem direita do Rio Mapuera. A aldeia é a maior entre outras 18 aldeias da região das terras indígenas Trombetas-Mapuera e Nhamundá-Mapuera, estas sofrem também com constantes migrações de habitantes nativos para as cidades próximas.

De acordo com Machado e Cordeiro (2016), a maioria das famílias que migram pertence à Aldeia de Mapuera. Na aldeia convivem diversos povos ${ }^{1}$, inclusive os Wai-Wais que se concentram como a maioria e possuem como dialeto oficial o Wai-Wai. Na busca para não perder o vínculo com a sua língua de origem, a escola da aldeia ensina à língua Wai-Wai e a língua portuguesa, sendo o português sua segunda língua.

Na aldeia a educação básica é dividida em ensino fundamental e médio. Coelho e Silva (2018) relatam que no ensino fundamental, do $1^{\circ}$ ao $5^{\circ}$ ano os professores são exclusivamente indígenas e as aulas são ministradas na língua Wai-Wai. Do $6^{\circ}$ ao $9^{\circ}$, as aulas são ministradas em língua portuguesa, por professores indígenas e não indígenas. O ensino médio é ofertado pelo sistema modular de ensino (SOME), com predominância de professores não indígenas. A Escola Indígena Wai-Wai tem aproximadamente 800 alunos matriculados, 580 no ensino fundamental e 220 no ensino médio.

Entretanto, muitas vezes o processo de ensino e de aprendizagem é prejudicado devido a dificuldades na comunicação entre professores e alunos, uma vez que se está diante de outra língua, a língua maternal Wai-Wai. Coelho e Silva (2018) relatam a dificuldade que os professores têm em repassar os ensinamentos de forma que todos os alunos compreendam, visto que assim como os professores têm dificuldades com a língua Wai-Wai, os alunos também têm com a língua portuguesa.

Além dos problemas citados, há escassez de métodos e materiais disponíveis que possam auxiliar na melhoria desses fatores, este trabalho apresenta um aplicativo baseado em realidade aumentada (RA) com uso de recursos visuais e auditivos com duplo objetivo: (1) atuar no auxílio do resgate cultural de jovens não aldeados que já esqueceram a sua língua nativa e (2) auxiliar no processo de ensino e de aprendizagem desses jovens.

O NativoApp vem para auxiliar o processo de ensino e de aprendizagem dos alunos indígenas Wai-Wai mais dinâmico, colaborativo e inovador. Deste modo, a tecnologia, vista antes como instrumento de distanciamento, é trabalhada de forma a

1 “...indígenas oriundos das etnias Wai-Wai, Hiskaryana, Tunayana, Katuena, tiriyó, Xereu,Manawana e Kaxuyana.”(Coelho e Silva, 2018). 
garantir a inclusão social e digital, servindo como meio de resgate, fortalecimento e preservação cultural, como busca Silva, I. et al. (2018).

O restante deste trabalho está organizado da seguinte forma: na Seção 2 são apresentados os trabalhos relacionados; na Seção 3 é apresentada a metodologia usada para o desenvolvimento do aplicativo proposto bem como a forma de avaliação; na Seção 4 são apresentados os resultados desse processo e, por último, na Seção 5 são feitas as considerações finais.

\section{TRABALHOS RELACIONADOS}

A RA já está presente nos ambientes de ensino aprendizagem, a exemplo disso tem-se o aplicativo Adoletras exposto no trabalho de Silva, T. et al. (2017). O mesmo se propõe a auxiliar no processo de alfabetização de crianças na faixa etária entre 6 e 7 anos por meio do projeto “Adoletras: Um jogo de Realidade Aumentada para auxiliar no processo de Alfabetização”.

Iniciativas voltadas para os indígenas envolvendo aplicativos ou ferramentas computacionais também são encontradas, como no trabalho de Silva, I. et al. (2018), que analisa o impacto do uso de tecnologia aplicada para uma atividade da disciplina de Guarani em uma escola multisseriada pertencente à Comunidade Indígena Nhu Porã.

Em Brito et al. (2017) é apresentado software TraduzIndio, um aplicativo de tradução de palavras indígenas para o português, desenvolvido por pesquisadores da Universidade Federal do Tocantins, que entre outros objetivos, tem o intuito de auxiliar a comunicação entre alunos indígenas e não indígenas.

O trabalho de Vicelli et al. (2019) apresenta parte dos resultados do projeto Guaruak, um aplicativo de línguas indígenas em desenvolvimento no Instituto Federal de Mato Grosso do Sul. O Guaruak permitirá traduzir línguas indígenas para o português e vice-versa, auxiliando na comunicação entre um grande número de grupos humanos.

\section{MÉTODO PROPOSTO}

O desenvolvimento do aplicativo se dá com base na Figura 1, onde se observa a representação de um sistema RA. O (B) marcador, neste caso se trata de um $Q R$ code, sua sigla do inglês Quick Response significa resposta rápida. Em português, é um código de barras bidimensional que quando escaneado pode retornar objetos multimídia como texto, link, imagens, etc. Diante da posição do marcador no (A) cenário, é possível projetar uma figura 3D no (C) hardware e software.

Para que ocorra a projeção da figura 3D, antes é necessária a criação de uma cena $^{2}$ em um ambiente de desenvolvimento. Quando o usuário inicia a aplicação e escaneia o marcador, este é identificado pela câmera do hardware e então o software faz a projeção dos elementos na tela. A Figura 2 representa este fluxo de funcionamento.

\subsection{CRIAÇÃO DO APLICATIVO}

2 É a composição da figura 3D ou/e outros elementos como textos 3D que são vinculados ao marcador. V. $17 \mathrm{~N}^{\mathrm{o}}$ 3, dezembro, 2019 RENOTE

DOI: 
No desenvolvimento do aplicativo, utilizou-se como ambiente de desenvolvimento a engine Unity versão 7, que vem com uma ferramenta no próprio editor de RA, o helloAR. É uma ferramenta multiplataformas, que possibilita distribuir o aplicativo gerado com melhor abrangência e alcance.

A geração de QR code foi feita de forma simples e gratuita no site $Q R$ code generator. Poderia utilizar-se outras imagens como marcador, no entanto o QR code foi escolhido pois através dele obtêm-se de forma fácil, rápida e precisa o reconhecimento pelo aplicativo.

Utilizou-se ainda o framework vuforia, que auxilia na criação de aplicações e projetos utilizando realidade aumentada, baseada em visão computacional para reconhecimento de imagens e objetos, e também foi utilizada a ferramenta Visual studio para edição de scripts e correção de eventuais bugs.

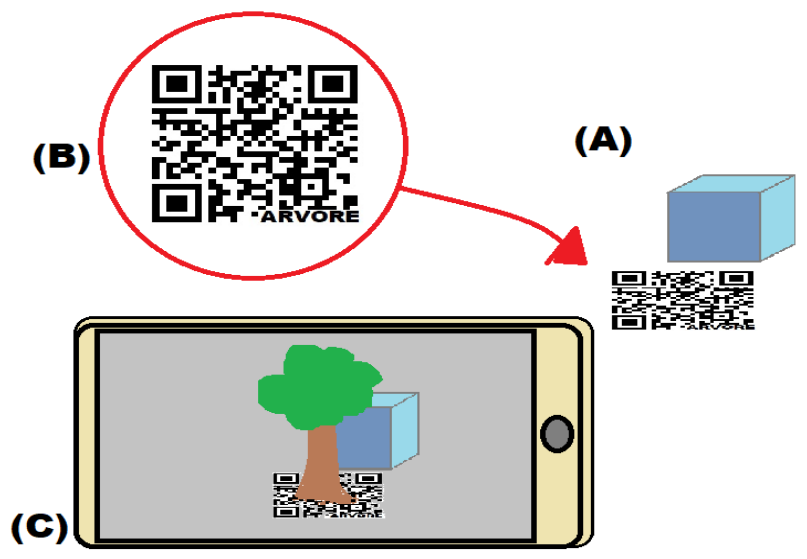

Figura 1 - Sistema de RA constituído por: (A) cenário, (B) marcador e (C) hardware e software.

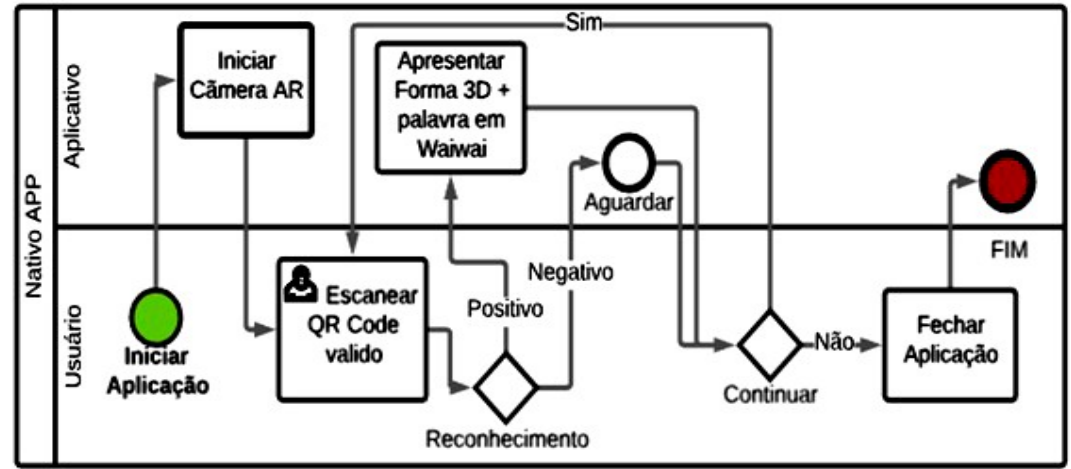

Figura 2 - Fluxograma do funcionamento básico do aplicativo.

As palavras selecionadas e utilizadas para criação das cenas no protótipo são frutos da colaboração de nativos da comunidade indígena Wai-Wai, que forneceram as palavras com os significados e os áudios das pronúncias. Já as imagens 3D utilizadas na elaboração das cenas foram adquiridas na biblioteca do Unity e de materiais gratuitos encontrados na internet. 


\subsection{APLICAÇÃo E ANÁLISE NO ÂMBITO EDUCACIONAL}

Foi solicitado previamente a autorização para aplicação do protótipo em ambiente educacional (escolas públicas de ensino fundamental e médio), visto que os participantes da pesquisa são crianças e adolescentes. Durante a pesquisa utilizou-se os métodos de observação e aplicação de questionário.

O questionário foi elaborado com total de 11 perguntas, no qual 5 eram de caráter objetiva (Q.01 à Q.05) relacionadas a interface e usabilidade do aplicativo e 6 utilizando a escala Likert (Q.06 à Q.11) relacionadas ao processo de ensino e de aprendizagem. No total participaram do experimento 21 alunos indígenas sob a supervisão de 6 educadores.

\section{RESULTADOS E DISCUSSÃO}

O aplicativo NativoApp consiste em uma aplicação educacional para plataforma móvel, cujo protótipo foi desenvolvido para Android e utiliza a câmera do dispositivo para identificar $Q R$ codes, impressos em cartões que referenciam determinados itens do cotidiano dos índios Wai-Wai, tais como: frutas, animais, artigos de artesanato e equipamentos de caça. A Tabela 1 demonstra algumas das palavras utilizadas para elaboração das cenas.

Tabela 1 - Palavras na língua Wai-Wai e o significado na língua Portuguesa

\begin{tabular}{|c|c|}
\hline Wai-Wai & Português \\
\hline Comota & Árvore \\
\hline Nuun̂i & Lua \\
\hline Reê̂e & Morcego \\
\hline Kaamo & Sol \\
\hline Xîrko & Estrela \\
\hline Roowo & Terra \\
\hline
\end{tabular}

A utilização é simples, basta que o usuário tenha o aplicativo instalado em seu smartphone e os QR code referentes às imagens cadastradas. Ao iniciar o aplicativo a câmera de RA é ativada automaticamente. O passo seguinte é apontá-la para o QR code impresso e então ver o resultado da imagem, assim como o seu nome em Wai-Wai. Para ouvir a pronúncia das palavras basta tocar no botão do áudio assim que este surgir na tela, conforme mostrado na Figura 3. 


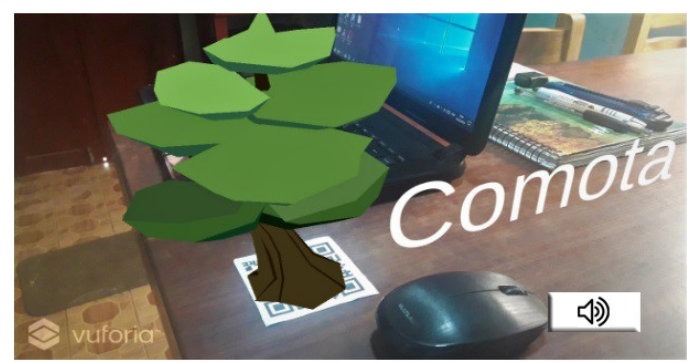

Figura 3 - Imagem da tela do aplicativo em execução no celular.

\subsection{APLICAÇÃO EM ÂMBITO EDUCACIONAL}

Esta etapa foi aplicada em escolas de ensino fundamental e médio da rede pública da cidade Oriximiná-PA onde existem alunos indígenas matriculados com o objetivo de avaliar o NativoApp no âmbito educacional. Desde de início o aplicativo foi muito bem recebido por educadores e alunos participantes da pesquisa.

Dessa forma, foi apresentado aos professores e alunos o objetivo da pesquisa, o funcionamento e o modo de utilização do aplicativo. De posse dos celulares com o aplicativo instalado e com os marcadores, foi aplicado as atividades para a utilização do Nativo APP.

Durante o desenvolvimento das atividades e a aplicação da pesquisa, foi observado o entusiasmo dos participantes, e obteve-se vários depoimentos dos alunos. Um desses alunos relatou a cobrança que sofria em casa por esquecer, algumas vezes, palavras do seu dialeto nativo. Enquanto outros se surpreenderam com palavras das quais não lembravam e ficavam felizes ao resgatar a cultura Wai-Wai e de vê-la refletida em um aplicativo móvel, de fácil utilização.

Santos e Rosa (2016) afirmam que "fazer uso dos recursos disponíveis para uma geração que já nasceu submersa nas novas tecnologias pode ser mais produtivo e eficiente”. Os autores dizem ainda que a boa utilização desses recursos estimulam o usuário a compartilhar e interagir com os demais, auxiliando no processo de ensino e de aprendizagem.

Os educadores, observaram com bons olhos o desenvolvimento do projeto e um deles, diretor de uma das escolas na qual foi aplicada a pesquisa, relatou ter trabalhado muitos anos como educador em aldeias indígenas e, para o mesmo, ver uma ferramenta voltada para esse público e com essa finalidade é algo, em suas palavras, "fantástico que pode ajudar muito".

Esta narrativa é reforçada no texto de Coelho e Silva (2018, p. 176) onde expõem o relato de um professor que diz que "se a gente falar uma palavrinha da língua deles (Wai-Wai), a gente consegue fazer com que eles entendam alguma coisa que queremos repassar em português”.

Após um período dedicado a uso e exploração da ferramenta por parte dos alunos, foi aplicado o questionário com base na experiência de uso do aplicativo. 


\subsection{SOBRE O APP E O LAYOUT DAS TELAS}

Resumidamente, podemos dizer que avaliação tem três grandes objetivos: avaliar a funcionalidade do sistema, avaliar o efeito da interface junto ao usuário e identificar problemas específicos do sistema (Vieira e Baranauskas, 2003, p.163). Deste modo, a primeira seção de perguntas do questionário objetiva avaliar os elementos apresentados no aplicativo segundo a perspectiva do participante, este tinha a opção de responder se o quesito analisado estava bom ou se precisa de alterações.

A primeira pergunta foi quanto ao tamanho dos botões. 19\% dos participantes responderam que está bom enquanto que $76 \%$ responderam que precisa aumentar e apenas $5 \%$ responderam que precisa diminuir. Já a segunda pergunta foi quanto ao tamanho da fonte e $81 \%$ responderam que está bom, 9,5\% responderam que precisa aumentar e outros $9,5 \%$ responderam que precisa diminuir.

Em seguida, a terceira pergunta foi quanto ao tamanho das figuras e $76 \%$ dos participantes responderam que está bom, $14 \%$ responderam que tem que diminuir e cerca de $10 \%$ responderam que tem que aumentar. A quarta pergunta, relacionada ao volume do áudio foi respondida com $47 \%$ dos participantes dizendo que está bom enquanto que $53 \%$ acham que precisa aumentar.

Na quinta pergunta, o quesito analisado foi a quantidade de vocabulários, onde a grande maioria, em torno de $90 \%$, respondeu que precisa aumentar e somente $10 \%$ informaram que está bom. Esses resultados são apresentados na Figura 4, onde a partir das respostas dos participantes da pesquisa foi montado um gráfico que representa os resultados obtidos.

\subsection{SOBRE O RECURSO EDUCACIONAL}

Faz-se necessário, portanto, discutir o uso de dispositivos móveis em sala de aula, sobretudo munidos de tecnologias emergentes, tais como, a RA, com vistas a consolidá-las como recursos importantes no processo de ensino e aprendizagem (Macedo e Goes, 2019). Para isso, esta seção buscou verificar as percepções do usuário acerca do recurso educacional disponibilizado.

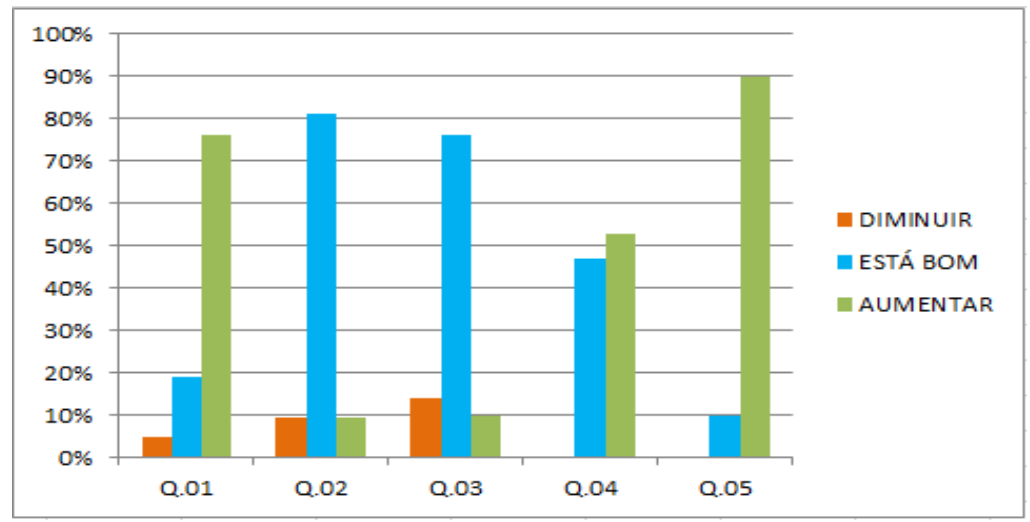

Figura 4 - Gráfico de análise de designer. 
Deste modo, esta seção da pesquisa foi elaborada utilizando a escala Likert, e os resultados obtidos são dispostos na Tabela 2. Vale ressaltar que foi utilizada para padronização das respostas a variação de 1 (discordo totalmente) até 5 (concordo totalmente). A tabela 2 e a Figura 5 demonstram o resultado da pesquisa com os 21 alunos participantes, desse total 19 deram nota máxima para o aplicativo, com destaque para as questões Q.06 e Q.10 que obteve nota 5 de todos os alunos.

Tabela 2: Perguntas sobre o recurso educacional

\begin{tabular}{|c|l|c|c|c|c|c|}
\hline$\#$ & \multicolumn{1}{|c|}{ Questões } & $\mathbf{1}$ & $\mathbf{2}$ & $\mathbf{3}$ & $\mathbf{4}$ & $\mathbf{5}$ \\
\hline Q.06 & $\begin{array}{l}\text { O recurso educacional utilizado permitiu adquirir novos } \\
\text { conhecimentos? }\end{array}$ & & & 21 \\
\hline Q.07 & $\begin{array}{l}\text { O recurso educacional utilizado permitiu consolidar } \\
\text { conhecimentos já existentes? }\end{array}$ & & 2 & & 19 \\
\hline Q.08 & Você utilizaria o aplicativo? & & 1 & & 20 \\
\hline Q.09 & O recurso educacional foi aplicado adequadamente? & 1 & & 1 & & 19 \\
\hline Q.10 & O APP ajuda no resgate cultural? & & & & 21 \\
\hline Q.11 & O aplicativo ajuda no processo ensino-aprendizagem? & & & 1 & & 20 \\
\hline
\end{tabular}

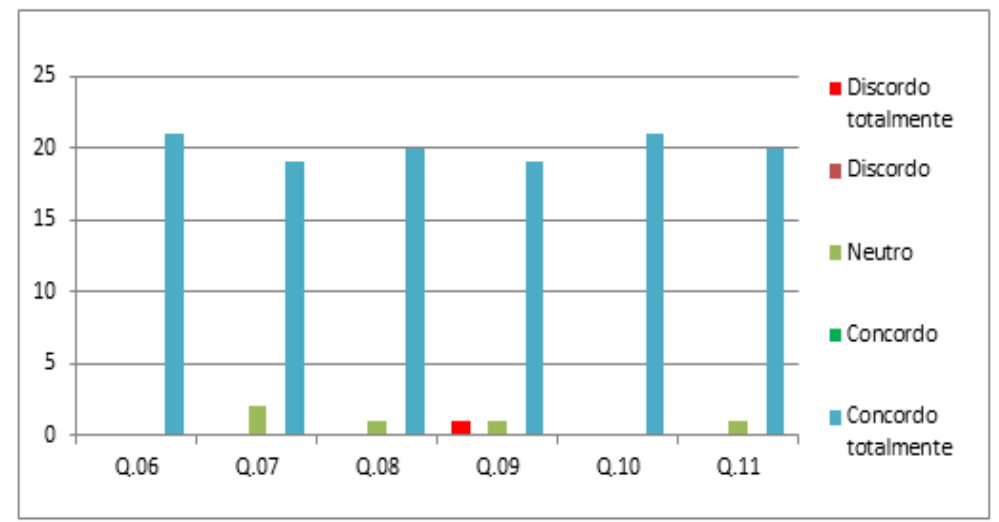

Figura 5: Gráfico representativo da Tabela 2

A Figura 6 demonstra o gráfico das médias obtidas em cada pergunta, cujo o desvio padrão das 6 perguntas apresenta média aproximada de 0,4 e receberam nota maior que 4,5 .

Os resultados demonstram que o aplicativo foi bem recebido, dadas as excelentes avaliações dos participantes. Vale ressaltar que nem todos os itens em avaliação obtiveram completa aceitação, e apesar da baixa proporção que isso representou, se estabelece um ponto de interesse para melhoria e aprimoramento de determinados quesitos. 


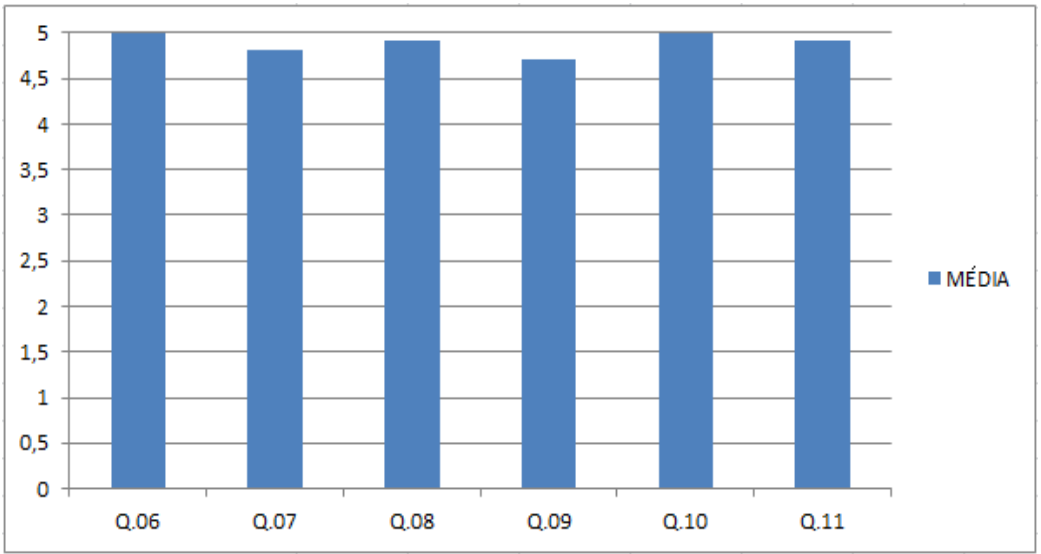

Figura 6: Gráfico da média das respostas de cada questão.

\section{CONSIDERAÇÕES FINAIS}

A introdução da tecnologia aliada ao conhecimento quando utilizada como auxílio nas práticas de ensino e de aprendizagem retorna bons resultados, o que estimula sempre a pensar em novas maneiras de enriquecer essas práticas, gerando ferramentas que podem ser utilizadas onde ainda há escassez desses recursos educacionais.

A realidade aumentada contribui no processo pois através dela cria-se a ilusão de que os objetos colocados de forma artificial se encontram de fato ali naquele local, despertando a curiosidade e interesse por parte do usuário para a informação ali apresentada tornando o aprendizado mais lúdico.

Alguns ajustes ainda precisam ser feitos para que a ferramenta possa de fato cumprir com excelência ao que se propõe, no entanto os resultados obtidos até aqui junto ao entusiasmo dos participantes motiva a continuação desse projeto. E como trabalho futuro pretende-se aumentar a quantidade de vocábulos, adicionar mais recursos e funcionalidade prosseguindo com o aperfeiçoamento da ferramenta, seguido de uma posterior avaliação mais ampla até uma eventual disponibilização para o grande público.

\section{REFERÊNCIAS}

BRASIL. Constituição (1988). Constituição da República Federativa do Brasil. In Vade Mecum Saraiva. 20a edição. São Paulo: Saraiva, 2015.

BRITO, George Lauro Ribeiro de et al. Mobile Platform for Translation of Brazilian Indigenous Languages of Tocantins, [S. 1.], 2017.

COELHO, Ana Cely de Sousa; SILVA, Messias Furtado da. Experiência pedagógica de professores Karaywa na aldeia indígena Mapuera, Oriximiná-PA. Revista Exitus, v. 8, n. 2, p. 163-188, 2018. 
IBGE. Censo 2010: população indígena é de 896,9 mil, tem 305 etnias e fala 274 idiomas - Disponível em: <https://censo2010.ibge.gov.br/noticias-censo.html?>. Acessado em: 28 mai. 2019.

MACEDO, Alex de Cássio; GÓES, Anderson Roges Teixeira. A integração da Realidade aumentada em sala de aula: a pesquisa aplicada em colégios públicos do litoral Paranaense. RENOTE 17, no. 1: 1-10. 2019.

MACHADO, A. A.; CORDEIRO, R. G. Patrimônio Cultural: Um resgate das histórias indígenas (lendas e mitos), contadas pelo povo da aldeia Mapuera. Trabalho de Conclusão de Curso - Universidade Federal do Oeste do Pará. 2016.

MICROSOFT. Visual Studio - As melhores ferramentas do setor para qualquer desenvolvedor. Disponivel em: <https://visualstudio.microsoft.com/pt-br/>. Acessado em: 18 mar. 2019.

QR Code Generator - Crie o seu código QR gratuitamente. Disponível em: <https://br.qr-code-generator.com/>. Acessado em: 10 jun. 2019.

SANTOS, Alex Lourenço dos; ROSA, Odelfa. O uso de aplicativos como recurso pedagógico para ensino de geografia. XVIII Encontros de geógrafos. Maranhão, 2016.

SILVA, Isabela Nardi da, et al. Uso de dispositivos móveis na disciplina de guarani para estudantes de uma escola multisseriada indígena. RENOTE 16.1 (2018).

SILVA, Tatyane; DA SILVA, Amanda; MELO, Jeane. Adoletras: Um jogo de Realidade Aumentada para auxiliar no processo de Alfabetização. In: Anais dos Workshops do Congresso Brasileiro de Informática na Educação. 2017. p. 206.

UNITY. Desempenho por padrão, gráficos de alta fidelidade em tempo real e ferramentas artísticas. Disponível em <https://unity3d.com/pt/unity>. Acessado em: 28 set. 2019.

VICELLI, Karina Kristiane; ROCHA, Carmem Silvia Moretzsohn; FALLEIROS, Evandro Luís Souza . Aplicativo de tradução Guaruak: Linguagem, memória e tecnologia aproximando povos. Web Revista Linguagem, Educação e Memória 16, $\mathrm{n}^{0}$. 16 (2019): 10-22.

VIEIRA, Heloisa; BARANAUSKAS, Maria Cecília C. Design e avaliação de interfaces humano-computador. Creative Commons, Brasil, 2003.

VUFORIA. Vuforia Engine 8.0 está disponível!. Disponível em: <https://developer.vuforia.com/ > . Acessado em: 18 de mar. 2019. 